\title{
DEVELOPED PROBABILISTIC REDUCTION FACTORS FOR LOPHIRA ALATA (EKKI) TIMBER JOISTS SUBJECTED TO CREEP-RUPTURE
}

\author{
J. M. Kaura ${ }^{1,}{ }^{*}$, A. Lawan ${ }^{2}$ and A. A. Salihu ${ }^{3}$ \\ 1, 2 Department of Civil EngineERIng, Ahmadu Bello University, Zaria, Kaduna STATE, Nigeria \\ 3 Department of Civil Engineering Technology, Nuhu Bamalli Polytechnic, Zaria, Kaduna State. Nigeria \\ E-mail addresses:1jmkaura@abu.edu.ng,2alawan@yahoo.co.uk,3adalgefans@gmail.com
}

\begin{abstract}
Wood experiences a significant loss of strength and stiffness when loaded over period of time. This phenomenon is known as creep-rupture. Several models were developed for the estimation of the reduction of load carrying capacity of timber with time. In this paper, the results of time dependent structural reliability analysis of timber joist produced with Lophiraalata (Ekki) timber specie was presented. Three load duration models were considered in the study, namely: The Model proposed by Wood, Gerhards model, and Nielsen. The timber joist was designed in accordance with the Eurocode 5. The uncertainties in all the basic design variables were fully accommodated in the time dependent reliability analysis. The entire process was implemented using a developed MATLAB program employing First Order Reliability Method (FORM). Time dependent mathematical models for modification of safety index to account for the effect of load duration were proposed. The use of both Gerhards and Nielsen model, for the design of Lophiraalata timber members was recommended.
\end{abstract}

Keywords: Creep-rupture, Lophiraalata, reliability, uncertainties, Gerhards

\section{INTRODUCTION}

\subsection{Preamble}

Wood experiences a significant loss of strength and stiffness when loaded over a period of time. This phenomenon is known as creep-rupture - often called the duration of load (DOL) effect $[1,2,3]$. The issue has been a subject of particular interest for everyone in the timber engineering community concerned with safe and efficient engineering design. Research on both clear wood [4] and structural timber [5, 6] sustaining longterm constant load is well documented in the literature. The load duration factors presented in the [7], like all other coefficients in the code were established based on the long term experience of building tradition based on semi-probabilistic approach [8]. In reality, the material properties of timber, such as density, bending strength, modulus of elasticity, tension and compression strength parallel and perpendicular to grain are highly random. The load duration effect is also a random variable [2]. The best way to model effects that are random (uncertain) is to use full probabilistic method [9]. With this in mind, probabilistic analysis was used to evaluate the effect of the load duration on timber considering timber floor joist made with Lophiraalata (Ekki) timber specie. The material properties of the timber specie were generated from the laboratory. First order reliability method was used through a developed MATLAB program to implement the structural reliability analysis. The reason for the selection of Lophiraalata timber specie is for its wide structural usage. Many structures like timber frame houses, timber Bridges and Railway sleepers were made of Lophiraalata.

Modification of the reliability indices rather than the timber material properties is proposed in this study. This is because safety indices are established after consideration of the uncertainties in the design variables and loading. The current recommended load duration factors $\left(\mathrm{k}_{\mathrm{mod}}\right)$ in the Eurocode 5 [7], only affects the material properties, being silent of the possible influence of load effect on the load duration.

Reliability-based design is performed to take into account, the effects of uncertainties and achieve predefined target safety indices. The effects of load duration on timber structures generally lead to non realisation of the target values of the safety indices, because, capacity of a timber structural member for a given failure mode is reduced with age. There is therefore the need to accommodate the loss of structural safety due to load duration effect in design. 
The overall aim of the present study is to develop time dependent mathematical models for modification of safety indices to account for load duration on Lophiraalata timber members, considering uncertainties in both material properties of the timber and the load action effects. The aim was achieved through the following objectives:

i. Generated statistical models (mean, coefficient of variation and statistical distribution models) of material properties of Lophiraalata timber specie based on experimental data.

ii. Generated statistical models of loading and geometrical properties for timber floor joist from data reported in the literature.

iii. Developed performance (limit state) functions for creep-rupture of simply supported floor joist, considering various load duration models reported in the literature (Woods (Woods, 1951), Gerhards (Gerhards, 1979) and Nielson models (Nielson, 1979).

iv. Developed MATLAB based First Order Reliability Analysis (FORM) program for the evaluation of the performance function to determine the safety indices at varying load duration for each of the considered load duration model.

v. Developed non-linear regression models for prediction of safety indices reduction due to creep rupture for timber floor joist.

\subsection{Modeling of the Duration of Load Effect}

Several models of load effect for timber and other materials can be found in the literature [2, 4-6, 10-18]. Some of these have a conceptual framework from some physical mechanisms leading to failure over time as a background; others are just empirically derived to represent load duration test data. One of the earliest creep rupture model was the one proposed by Wood in 1951 [4]. This model was formulated on the basis of results from laboratory tests on clear wood bending specimens, exposed to loads of constant intensity. Medison curve was then developed based on the following empirical model:

$$
s l=90.4-6.3 \log t_{f}
$$

In (1), $s l$ is the stress level and $t_{f}$ is the time to failure in hours. What were popularly known as 'damage accumulation models' for creep rupture were proposed by some notable researchers. The most prominent damage models are those proposed by Gerhaard's [13] and Foschi [12].The mathematical expression of Gerhard's model for calculating damage accumulation of a timber member with initial capacity, $\mathrm{R}_{0}$ sustaining a load $\mathrm{S}(\mathrm{t})$, is given by the following equation:

$$
\frac{d \alpha}{d t}=e^{(-a+b) \varsigma} \text { for } 0 \leq \alpha \leq 12
$$

In (2), $\varsigma=\frac{S(t)}{R_{0}}, \alpha$ is the degree of damage ( $\alpha=0$ denoting no damage and $\alpha=1$ denoting failure) a and $b$ are model parameters. Equation 3 shows the mathematical expression of Foschi and Yao's model for calculating damage accumulation of a timber member with initial capacity, $\mathrm{R}_{0}$ sustaining a load $\mathrm{S}(\mathrm{t})$.

$$
\begin{gathered}
\frac{d \alpha}{d t}=A\left(\frac{S(t)}{R_{0}}-\eta\right)^{B}+C\left(\frac{S(t)}{R_{0}}-\eta\right)^{D} \alpha(t) \text { for } S(t)>\eta R 3 \\
\frac{d \alpha}{d t}=0 \text { for } S(t) \leq \eta R_{0}
\end{gathered}
$$

In (3), A, B, C and D are model parameters. Other creep rupture models were developed based on fracture mechanics. Typical is the one proposed by Nielsen in 1979 [16]. The idea behind the Nielsen model is that structural timber may be seen as an initially damaged viscoelastic material, with the load-carrying capacity $R_{0}$, where the damage is represented by cracks along the fibres. The time-dependent behaviour of timber under load is modeled by a single crack under stress perpendicular to the crack plane. For the case of a constant load level, S a damage accumulation law can be formulated from the DVM-model as:

$$
\frac{d \alpha}{d t}=\frac{(\pi F L)^{2}}{R_{0}} \alpha_{k} \frac{(S)^{2}}{R_{0}}\left[\alpha_{k}\left(\frac{(S)^{2}}{R_{0}}\right)^{-1}-1\right]^{(-1 / b)}
$$

In (5) FL is the strength level defined as the ratio $\sigma_{\mathrm{cr}} / \sigma_{\mathrm{i}}$ between the short term strength, $\sigma_{\text {cr }}$ measured in a very fast ramp test and the intrinsic strength of the (hypothetical) non-cracked material $\sigma_{\mathrm{i}}$. The damage, $\alpha_{\mathrm{k}}$ is defined as the ratio between the actual crack length, l, and the initial crack length $l_{0} . \alpha_{\mathrm{k}}=1$ corresponds to no damage and $\alpha_{k}\left(\frac{(S)^{2}}{R_{0}}\right)^{-1}$ to full damage. $\tau$ and $\mathrm{b}$ are creep material parameters. $\mathrm{q}$ is given as a function of creep exponent $q=(0.5(b+1)(b+2))^{(a / b)}$ and considers a parabolic increasing crack propagation.

\section{MATERIALS AND METHODS \\ 2.1 Material}

The programme of tests was designed to determine the bending strength, modulus, density and moisture content of Lophiraalata (Ekki) timber species. Four point bending test was conducted in accordance with [19]. The materials were obtained from Sabongari Zaria timber sheds, Kaduna State. 


\subsection{Experimentation}

Fourty samples were used for both the density and the bending tests based on the EN 384 [20] specification on the required number test specimens. The density and the moisture content tests was conducted according to EN 13153-1 [21], while the bending tests were conducted according to EN 408 [20]. All the tests were done at the heavy duty structures laboratory of the Department of Civil Engineering, Ahmadu Bello University, Zaria. The generated data were analyzed based on EN 384 [20], to determine the mean values and coefficients of variation of the material properties and density. Kolmogorov Smirnov (KS)test was conducted using Easyfit [22] statistical analysis software to fit the most appropriate distribution model to the material properties and the density.

To facilitate the grading of the Lophiraalata timber specie in accordance with EN 338 [23], the density, bending strength and modulus of elasticity were adjusted to $12 \%$ moisture content using Equations (6), (7) and respectively [24, 25, 26]:

$$
\begin{gathered}
f_{m, 12 \%}=\frac{f_{\text {measured }}}{1+0.0295(12-u)} \\
E_{12 \%}=\frac{E_{\text {measured }}}{1+0.0143(12-u)} \\
\rho_{12 \%}=\rho_{u}\left(1-\frac{0.5(u-12)}{100}\right)
\end{gathered}
$$

In (6), (7) and (8), $\mathrm{f}_{\mathrm{m}, 12 \%}$ is the bending strength at $12 \%$ moisture content. $f_{\text {measured }}$ is the bending strength at the measured moisture content. $\mathrm{u}$ is the measured moisture content in $\%, \mathrm{E}_{12}$ is the $12 \%$ moisture content adjusted modulus of elasticity, $\mathrm{E}_{\text {measured }}$ is the measured modulus of elasticity, $\rho_{12}$ is $12 \%$ moisture content adjusted density, $\rho_{\mathrm{u}}$ is the measured density.

\subsection{Structural Reliability Analysis}

The most probable point (MPP) method is employed for the probabilistic analysis in this study. Based the data on material properties and loading defining the performance function of a given mode of failure, suitable distribution laws (normal, lognormal, uniform, Weibull, Gumbel) are selected. Then the random variables were transformed into a standard normalized space. For the transformation, the mean value and the standard deviation of the random variables are necessary. This information is presented in Table 1.

In the standard normalized space, a normalized vector $U$, can be calculated by: $U=T(y)$, where $T(y)$ is the probabilistic transformation function. For a given scenario, the reliability index $\beta$, introduced by Hasofer and Lind in 1974 is evaluated by solving a constrained minimization problem:
In (9), $U$ is the vector modulus in the normalized space, measured from the origin. Figures 1 and 2 shows the physical and the normalised space respectively

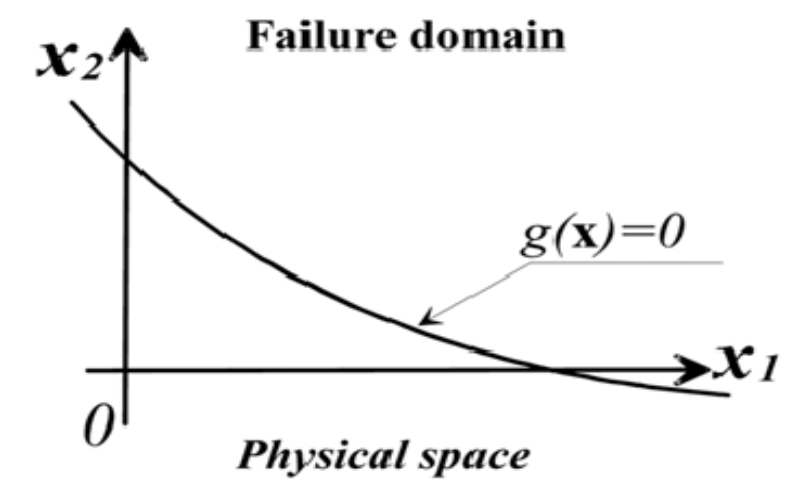

Figure 1: Physical space

Figure 2: Normalised apace

The minimum distance $d(U)$ is given by :

$$
d=\sqrt{\sum U_{i}^{2}} i=1, \ldots \ldots, n
$$

where $\mathrm{n}$ is the variable number.

The solution of the constrained optimisation problem (Equation 10), define the design point $P^{*}$. The resulting minimum distance between the limit state function $\mathrm{H}(\mathrm{U})$ and the origin is called the reliability index, which in general can be obtained in terms of the probability of failure $\mathrm{P}_{\mathrm{f}}$ given by:

$$
\beta=\phi^{1}\left(P_{f}\right)
$$

The flow chart for the MATLAB implementation of the MPP method is presented in Figure 3.

\subsection{Structural Configuration of the Lophiraalata Floor Joists}

Timber floor joists for a domestic dwelling (Figure 4) produced with Lophiraalata (Ekki) timber specie were considered for the time-dependent reliability-based determination of the safety index modification factor. The width of the floor b, is $3.6 \mathrm{~m}$ and the floor span, l, is $3.4 \mathrm{~m}$.

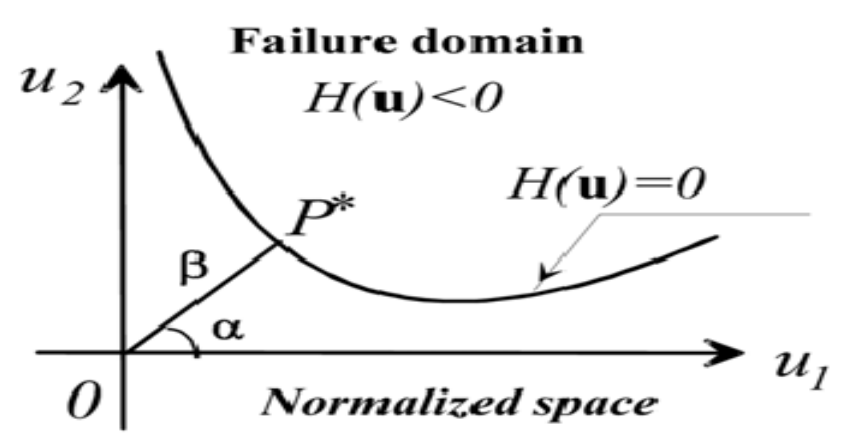


Table 1: Stochastic models of the basic design variables

\begin{tabular}{|c|c|c|c|c|c|c|}
\hline S/No & Variable & Unit & Variable Type & $\begin{array}{l}\text { Coefficient of } \\
\text { Variation }\end{array}$ & $\begin{array}{l}\text { Distribution } \\
\text { Model }\end{array}$ & Reference \\
\hline 1 & $\begin{array}{l}\text { Resistance Model } \\
\text { Uncertainty, } \phi_{\mathrm{R}}\end{array}$ & - & Random & 0.1 & Lognormal & [9] \\
\hline 2 & Creep Rupture Model, $\lambda_{d}$ & - & Random & 0.15 & Lognormal & [9] \\
\hline 3 & Bending Strength, $\mathrm{f}_{\mathrm{m}}$ & $\mathrm{N} / \mathrm{mm}^{2}$ & Random & 0.16 & Lognormal & [9] \\
\hline 4 & $\begin{array}{l}\text { Load action model } \\
\text { uncertainty, } \phi_{\mathrm{s}}\end{array}$ & - & Random & 0.1 & Lognormal & Test reslts \\
\hline 5 & Variable load, $\mathrm{Q}$ & $\mathrm{kN} / \mathrm{m}^{2}$ & Random & $0.2-0.4$ & Gumbel & {$[27]$} \\
\hline 6 & Dead to live load ration, $\alpha$ & - & Deterministic & - & - & - \\
\hline 7 & Joist span, L & M & Deterministic & - & - & - \\
\hline 8 & Joist width, b & $\mathrm{Mm}$ & Random & 0.05 & Normal & {$[28]$} \\
\hline 9 & Joist Depth, $\mathrm{d}$ & $\mathrm{Mm}$ & Random & 0.05 & Normal & {$[28]$} \\
\hline
\end{tabular}

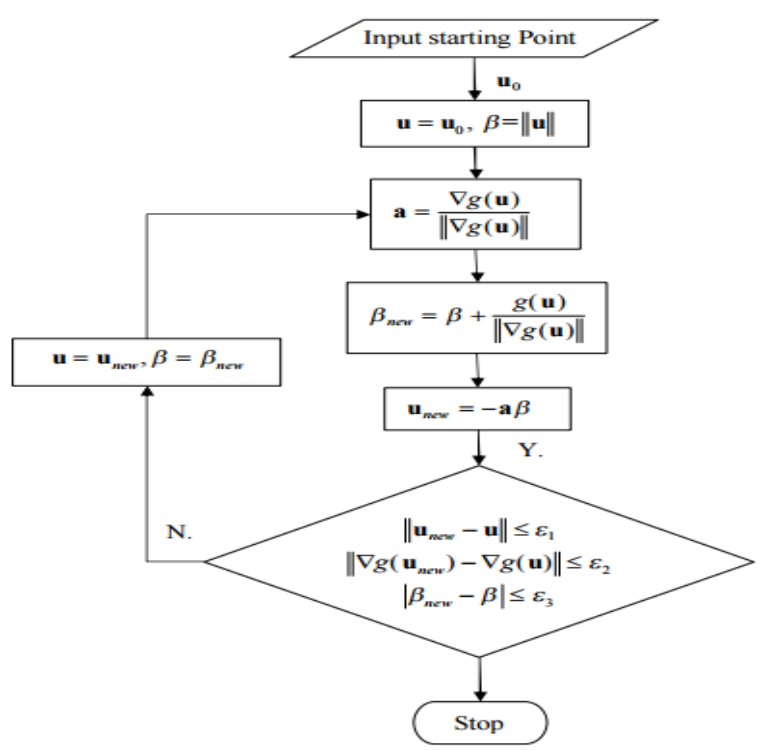

Figure 3: Flow chart for the MATLAB implementation of the MPP method

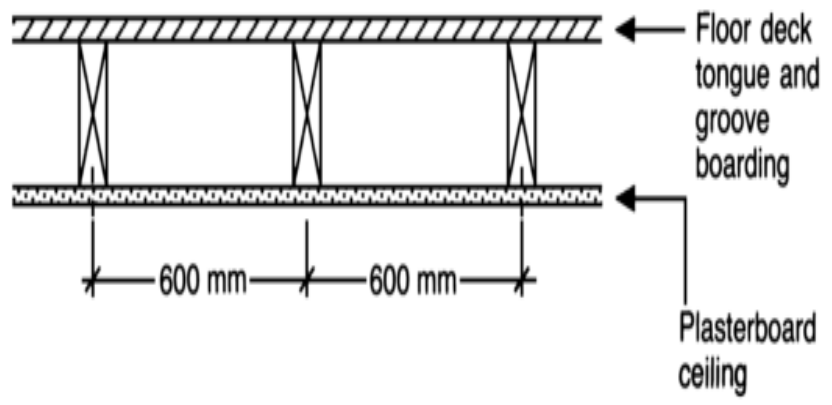

Figure 4: Structural Model of the Flooring System Fracture Mechanics Model

The joists are spaced at $600 \mathrm{~mm}$ centres. It was subjected to characteristic variable action of $1.50 \mathrm{kN} / \mathrm{m}^{2}$ with permanent to variable load ratio defined by alpha $(\alpha)$. The design of the joist according to Eurocode 5 revealed that timber joists with width b equal to $50 \mathrm{~mm}$, and depth $\mathrm{h}$, equal $150 \mathrm{~mm}$ spaced $600 \mathrm{~mm}$ would be adequate.

\subsection{The Flexural Limit State Function}

The structural reliability analysis requires the formulation of the performance function for the failure mode of interest. In this study, only flexural limit state function is considered. The limit state function is given by Equation (13)

$$
G(x)=\phi_{R} \lambda_{d} f_{m}-\frac{2.25 e^{4} Q(\alpha+1) L^{2}}{b d^{2}}
$$

In (13), $\phi_{\mathrm{R}}$ is the model uncertainty for bending resistance, $\lambda_{d}$ is the creep-rupture model, $f_{m}$ is the bending strength of the Lophiraalata timber joist, $\phi_{\mathrm{s}}$ is the model uncertainty for the load action, $Q$ is the variable load action, $\alpha$ is the dead to live load ratio, $\mathrm{L}$ is the joist span in $\mathrm{m}, \mathrm{b}$ and $\mathrm{d}$ are joist width and depth respectively in $\mathrm{mm}$. The Lophiraalata timber species was classified into timber strength class D60, according to EN 338 [23].

\subsection{Determination of the Safety Index Reduction Factor due to Creep Rupture}

The floor joists considered were first designed according to Eurocode 5, [7], with the load duration factor $k_{\bmod }$ taken as 1 . The flexural failure mode of the joists was then subjected to structural reliability based design, and the safety index was found to be 5.92 corresponding to the Eurocode 5[7] criteria for the design load. The computed safety index is above the Eurocode 0 [8] recommended minimum safety index of 3 .

Three damage models proposed by Wood [4], Gerhards [13] and Nielson [16] were used to evaluate the time dependant capacity reduction of safety indices due to creep rupture. The structural reliability analysis was conducted considering each of the three models. The time dependent capacity reduction as measure of reduction of joist safety is obtained by Equation (14).

$$
C R(t)=\frac{\beta_{i}(t)-\beta_{r}(t)}{\beta_{i}(t)}
$$

The time dependent capacity modification factor is the compliment of the time dependent capacity reduction factor, $\mathrm{CR}(\mathrm{t})$, given by Equation (15).

$$
\lambda_{d}(t)=1-C R(t)
$$

Here, $\mathrm{CR}(\mathrm{t})$ is the time dependent capacity reduction, $\beta_{i}(t)$ is the safety index of the just constructed timber 
joist, $\beta_{\mathrm{r}}(\mathrm{t})$ is the time dependent safety index of the joist, $\lambda_{d}(t)$ is the time dependent safety index modification factor, $t$ is the age of the joist from erection in years.

Investigation was made for up to 50 years load duration, and the results subjected to non-linear regression analysis. Time dependent mathematical models for the safety index modification were developed for Wood, Gerhards and the Nielsen models.

\section{RESULTS AND DISCUSSION}

The results of the time dependent structural reliability analysis of the effect of load duration on timber members are presented in Figures 5 to 8.

The relationship between safety index and load duration of timber corresponding to the three considered damage models (Wood model, Gerhards model and Nielsen models) is presented in Figure 5. It is clear from the plot that, the relationship is non-linear. The model proposed by wood, shows very high capacity reduction at all ages. For instance at the 40 years load duration the Wood model gave safety index on 2.5, while the Gerhards and Nielsen models gave safety indices of 3.15 and 3.2 respectively. Structural reliability using the Eurocode 5 recommended load duration factors $\mathrm{k}_{\text {mod }}$ for long term action, gave safety index of 3.03. Since 40 years is within the long term action category of the Eurocode 5, it can be concluded that, the Gerhards and the Nielsen models closely predicted the Eurocode 5 load duration effect

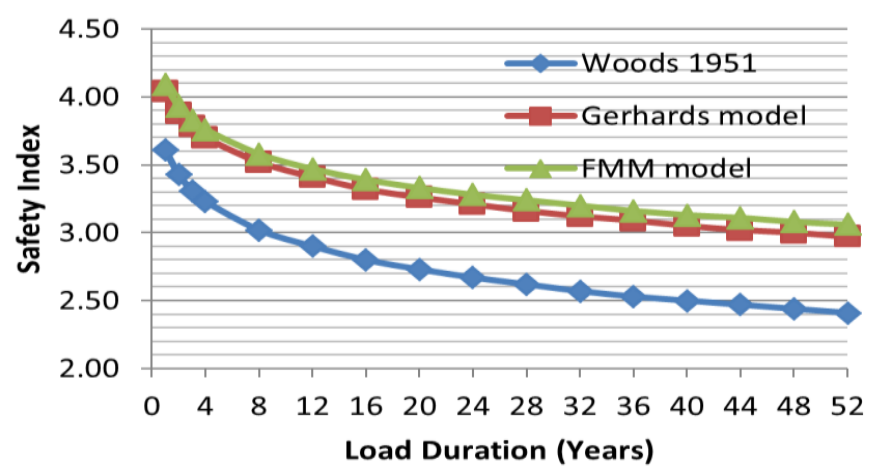

Figure. 5: Effect of load duration on safety index for various damage models

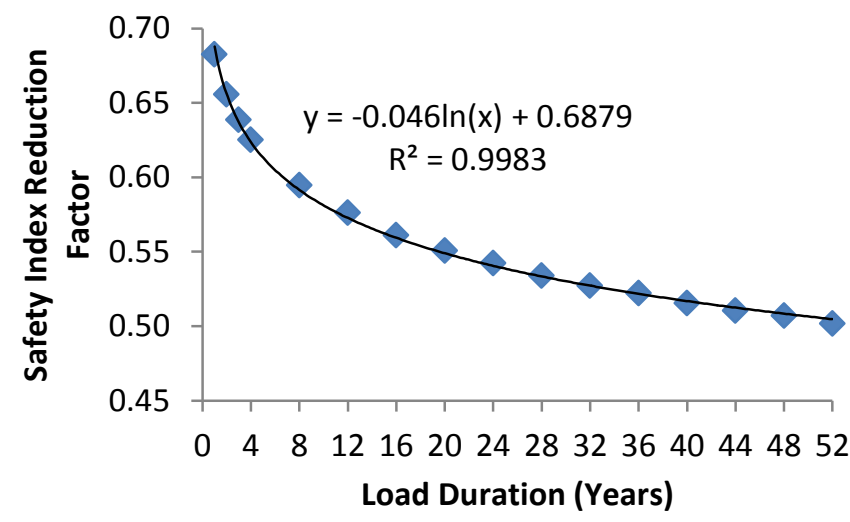

Fig. 7: Non-Linear regression plots for Safety index reduction model (Gerhards model) proposal. The Wood model however, over-estimated the load duration effect.

Figure 6, 7 and 8 presented the non-linear regression plots for the Wood, Gerhards and Nielsen models respectively.

Based on the results presented, the following mathematical models were developed for reduction of safety indices obtained from structural analysis due to load duration for timber member produced with Lophiraalata timber specie:

i) based on Wood model:

$$
\lambda_{d}(t)=-0.005 \ln (\mathrm{t})+0.615
$$

(ii) based on Gerhard model

$$
\lambda_{d}(t)=-0.04 \ln (\mathrm{t})+0.70
$$

(iii) based on Nielsen model

$$
\lambda_{d}(t)=-0.04 \ln (\mathrm{t})+0.615
$$

The $\mathrm{R}^{2}$ values for all the models were found to be 0.998 , indicating strong correlation between the safety index reduction factor and the load duration.

\section{CONCLUSION}

In this study, the results of reliability-based evaluation of the effect of load duration on timber members produced with Lophiraalata timber specie were undertaken. Mathematical models for reduction of computed safety indices from structural analysis were developed considering three damage models reported in the literature (Wood, Gerhards model and Nielsen models).

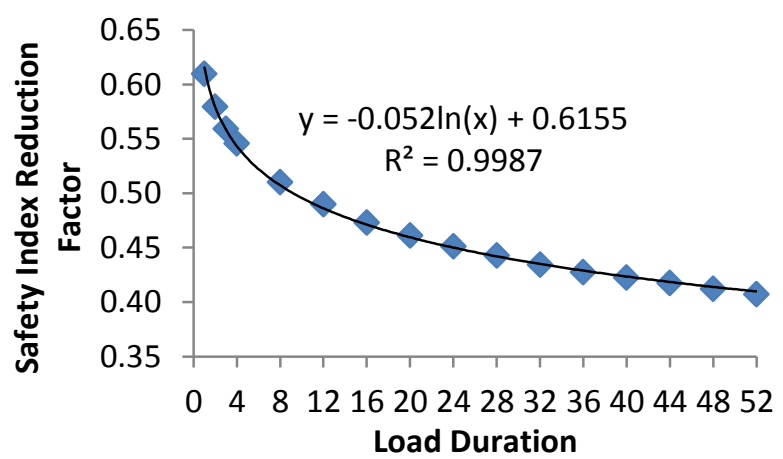

Fig. 6: Non-Linear regression plots for Safety index reduction model (Woods, model)

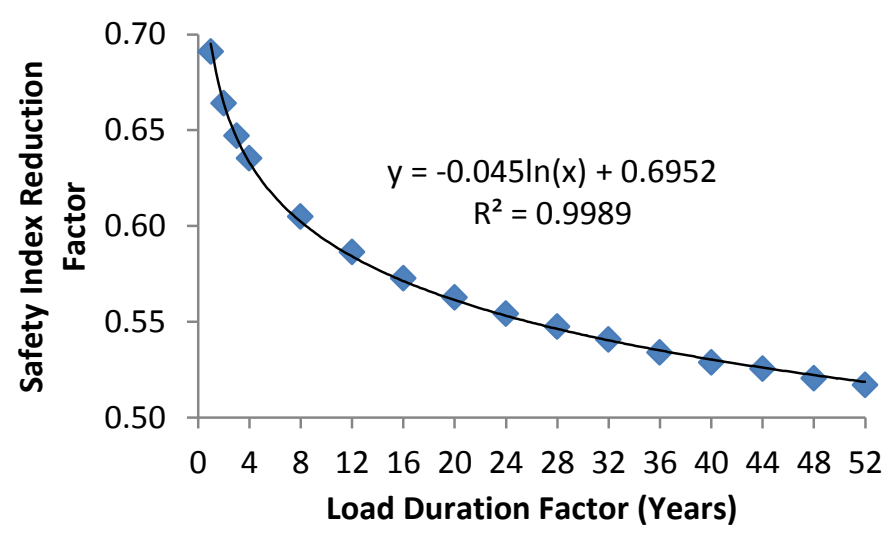

Fig. 8: Non-Linear regression plots for Safety index reduction model (Nielsen model)

Vol. 36, No. 1, January 2017 
It should be noted that, the Woods model is based on test performed on small clear timber specimen (free of defect), while the Gerhardsand Nielsen models were based of test results performed on structural timber. Timber design codes that are based on permissible stress methods, such as the Nigerian code of practice for timber [26], use material properties obtained from tests on small clear timber specimen, while the material properties for limit state design related codes such as EN 338 (2009) are based on test on structural timber. With this in mind, the use of the capacity reduction factors for safety indices derived based on Gerhards and Nielsen models is recommended for design of Lophiraalata timber structural members with the Eurocode 5.

\section{REFERENCES}

[1] Toratti T. Turik G. and Schnabi S. 'Reliability Analysis of Glulam Tapered Beam'. Technical Research Centre of Finlab.VTT Building and Transport. 2004.

[2] Kohler, J. and Svensson, S.. 'Probabilistic Modeling of Duration of Load Effects in Timber Structures'. 35, CIB W18 Meeting, Kyoto, September, 2002

[3] Larsen H. J. 'Properties affecting reliability design of timber structures. An overview prepared for the COST E24 Seminar on Reliability of timber structures'. Coimbra, Portugal, 4 - 5 May 2001, 2001.

[4] Wood L. W. 'Relation of Strength of Wood to Duration of Stress'. U. S. Forest Products Laboratory. Report No. 1916. 1951.

[5] Hoffmeyer, P. 'Failure of Wood as Influenced by Moisture and Duration of Load'. PhD Thesis. College of Environmental Science and Forestry Syracuse, State University of New York. 1990.

[6] Madsen H. 0. 'Structural Behaviour of Timber'. Timber Engineering Ltd. Vanvouver, Canada. 1992.

[7] Eurocode 5' Eurocode 5: Design of Timber Structures Part 1-1: General -Common Rules for Buildings'. CSI, Prague, December 2006. 2004.

[8] Eurocode 0 Eurocode-Basis of structural design. British standards'. CEN Brussels. 2004.

[9] Mohammed J. K., and Abubakar, I. 'Safety Variations of the Eurocode 5 Design Criteria of Solid Timber Column Using Genetic Algorithms'. Proceeding of the $3^{\text {rd }}$ Annual Civil Engineering Conference, Department of Civil Engineering, University of Ilorin, 6 - 8 July, 2011. pp. 111-122. 2011.

[10] Barrett, I. D. and Foschi, R. O. 'Duration of Load and Probability of Failure in Wood.Part I + II', Canadian Journal of Civil Engineering, 5(4): 505-532. 1978.

[11] Elligngwood, B. and Rosowsky, D. V. 'Duration of Load Effects in LRFD for wood Constructions'. ASCE J. Struct. Eng. 117(2): 584-599. 1991.

[12] Foschi R. O. and Yao, Z. C.. 'Another look at three duration of load models'. Proc. $19^{\text {th }}$ CIB/W18 Meeting, Florence, Italy. 1986.
[13] Gerhards C. C. 'Time-related Effect of Loading on Wood Strength. A Linear Cumulative Damage Theory'. Wood Sci. 10(3): pp. 139-144 1979.

[14] Gerhards C. C. and Link, C. L. 'A Cumulative Damage Model tp Predict Load Duration Characteristic in Timber'. Wood Science. 19(2): 139-144. 1987.

[15] Lindley, D. Y. 'Introduction to Probability and Statistics', Cambridge University Press. The philosophy of statistics. J. Roy Statist Soc: Ser D (The Statistician) 2000: 49(3): pp. 293-337. 1965.

[16] Nielson L. F. Crack Failure of Dead, Ramp and Continued Loaded Viscoelastic Materials' Proc. First International Conference on Wood Fracture. Baniff, Alberta, Canada. 1979.

[17] Sorensen, J. D., Hansen S. O., and Nielsen T. A. 'Partial Safety Factors and Target Reliability Level in Danish Codes'. In: Safety, Risk and Engineering Conference Report, IABSE. 2002.

[18] SvenssonS Thelandersson S. and Larsen H. J. 'Reliability of Timber Structures Under Long-term Loads'. Material and Structures. 32: pp. 755-760. 1999.

[19] EN 408 'European Standard: Timber structures Structural Timber - Determination of some physical and mechanical properties'. 2004, ComitéEuropéen de Normalisation, Brussels, Belgium. 2004.

[20] EN 384 'Timber Structures; Structural timber Determination of characteristic values of mechanical properties and density'. 2004, ComitéEuropéen de Normalisation, Brussels, Belgium. 2004.

[21] EN 13153-1 Moisture Content of a Piece of Sawn Timber-Part 1.Determination by Oven Dry Method. 2002.

[22] Easyfit Statistica Software for Data fitting. Mathwave Technologies. Downloaded at http://www.mathwave. com/en/home.html, $6^{\text {th }}$ August, 2015.

[23] EN 338 'Structural timber - Strength Classes'. European Committee for Standardization. Austrian Standards Institute Heinestrabe 38, 1020 Wien. 2009.

[24] Kupera, B. Skandinaviskenormer for testing avsmåfeilfrieprøveravheltre.Skogsforsk, Norwegian Forest Research Institute. Agricultural University of Norway. 104 p. (In Norwegian) 1992.

[25] Boström, L. Machine Strength Grading, Comparison of Four Different Systems. Swedish National Testing and Research Institute, Building Technology SP, Report 1994: 49.57 p. 1994.

[26] NCP Nigerian standard code of practice , NCP 2: Grade stresses for Nigerian Timbers 1973.

[27] Ellingwood, B., Galambos, T. V., MacGregor, J. G., and Cornell, C. A. Development of a Probability-Based Load Criterion for American National Standard A58, NBS Special Publication 577, National Bureau of Standards, Washington, D. C. 1980.

[28] Afolayan, J. 0. 'Probability-based design of glued thinwebbed timber beams'. Asian Journal of Civil Engineering (Building and Housing). 4(1-2): pp 75-84. 2005. 